\title{
1. Introduction: status, superstars and markets
}

\section{THE CONSUMPTION OF STATUS GOODS AND THE GROWTH OF TOP EARNERS}

One important aspect of modern life is that middle-class individuals participate in Veblenian consumption excesses for status goods and have become more willing to be involved in occupational markets, which are monetarily rewarding but risky. These markets are characterized by tournament dynamics, which exhibit greater failure rates and produce highly rewarded and visible professionals or superstars. Consumption excesses were in the past common only among members of the upper class but today they are evident in the behaviour of individuals from the middle class and even from the working class.

Overconsumption does not result only in greater levels of aggregate demand but causes higher sales for highly priced goods and services. After all, today there is an abundance of expensive consumption goods and services to choose from. Expensive watches, summer vacations to Ibiza, Florida, the Caribbean islands and other exotic destinations, brand clothing such as Abercrombie and Fitch or Benetton, gourmet dinners at fancy restaurants are all examples of expensive goods and services, which contribute to a different lifestyle from the average main-street or neighbourhood outlet experience. Such indulgences have now become an indispensable part of life for many. In addition, it is evident that buying expensive cars or SUVs (sports utility vehicles), bigger or new houses in the suburbs and often a summer house or a holiday home are not just dreams for the distant future. Such considerable household expenses for durable goods are quite common for middle-class individuals and families today. Thus the emergence of lifestyle consumption as an important aspect of contemporary life cannot be easily ignored.

The middle class follows a variety of consumption patterns that are influenced by new lifestyle preferences. However, the origin of those preferences is not arbitrary. On many occasions, these preferences are similar to the trends followed by the superrich in various forms of their 
consumption such as for prime housing locations or luxury cars. Excessive lifestyle consumption for the middle class relates to what has been labelled in the past as conspicuous consumption. This term, which was introduced by Thornstein Veblen at the turn of the nineteenth to the twentieth century, was not confined only to the excesses of the superrich at that time. Veblen was aware that excess consumption in general relates to the self-worth of the consumers. He argued that feelings of inferiority and dishonour are generally associated with the failure to consume. ${ }^{1}$

The strength of conspicuous consumption nowadays is caused by objective factors such as the liberalization of the credit system and the growth in earnings. This form of consumption is enjoyed not only by individuals who already belong to the upper classes, but also by the growing numbers of professionals in different occupations such as, dentists, lawyers, actors, media personalities, consultants, sports players and others. In addition, the growth in earnings for the middle class has surely contributed to conspicuous consumption. A considerable share of the excessive consumption not only of the elite but also of the middle class, is directed towards positional or status goods. These goods are valued better the more advantageously they compare with the items consumed by others. ${ }^{2}$

Various terms have been attributed at different times to describe the goods and services that are influenced by these behavioural patterns and forces. The most common definitions are status or positional goods and the segments of the markets in which they are traded are called status or positional markets, which are characterized by relative comparison concerns. Status goods and services appear in homogeneous markets when people's preference for buying them increases as a direct function of their price. The underlying motivation for such a preference is often the desire of individuals to acquire distinction. In heterogeneous markets, status goods and services are different from standard items because they are valued not according to their absolute properties, but according to how they compare with the goods or services consumed by others.

The high growth in earnings materializes also because the market today attributes a higher value on the services of highly visible top performers, the superstars in those occupations. However, the markets that produce famous highly paid performers, the markets of superstars are different than traditional markets. High visibility is a quality that makes top performers realize earnings that are much greater than the compensation expected from their absolute performance or contribution at work. The number of highly paid workers has increased rapidly even as the average white-collar job has been barely keeping up with inflation. In 2002, the size of the annual earnings in the USA, which corresponded to 
the top 1 per cent of the population in terms of income was about US\$286 000. By 2011, according to the US Internal Revenue Service, the size of the annual earnings to make it into the top 1 per cent of the population in terms of income skyrocketed to around US\$506000. Obviously, those professionals were members of a special elite social group, which mainly included doctors, lawyers, executives and managers, sales supervisors and representatives, accountants, consultants as well as arts and entertainment professionals including writers, actors, musicians, artists and athletes.

This phenomenon has received considerable attention during the past three decades following the seminal work of Rosen on superstars. ${ }^{3}$ Subsequently, Frank and Cook introduced in the context of labour markets the concept of 'winner-take-all' markets, which are one of the outcomes associated with the advent of the super high earnings for top performers. Frank and Cook's research utilizes a microeconomic analysis, which emphasizes the rewards received by those top professionals for their relative advantage in performance. This view contradicts the traditional economic wisdom, in which rewards are the result of absolute performance of workers. In addition, this framework differs considerably from the traditional static economic analysis because it uses findings from behavioural approaches such as social psychology in a way that compares to rational behaviour. Later on, the examination of the superstar phenomenon in labour markers was enhanced by Frank's analysis of luxury consumption. In this analysis, three important distortions that motivate individuals to be involved in positional consumption are identified: advertising, adaptation and the attractiveness of luxury per se.

However, in the mainly mainstream approaches on status and superstars, positional consumption is dealt with largely within a framework that is highly compatible with rational behaviour and policies are confined to general horizontal public programmes, which raise welfare for all. The design of social policies that provide greater value to the underprivileged is absent. Subsequent attempts to introduce inequality in the analysis are highly constrained by the fact that the proposition of horizontal social policy measures is maintained. ${ }^{4}$ Instead, a focus on a behavioural framework could explain better the nature of distortion in the endogenous formation of preferences in status markets and help design appropriate social policies with respect to status and superstar markets, which address better the issue of inequality. These policies respond to the fact that although the rich have stronger incentives to be involved in activities of superstar markets, it is the poorer that experience greater financial losses relative to their incomes and substantial human distress from their participation in status tournaments. 


\section{SUPERSTARS, MARKETS AND BEHAVIOURAL FORCES}

The consumption of status goods and services reflects lifestyle preferences that to a great extent involve discriminatory judgement. Besides objective factors such as the increase in earnings, conspicuous consumption is attributed also to behavioural forces that influence preferences. Specific consumption preferences and lifestyle practices reflect different occupations and class fractions. In these consumption practices, the object of purchasing is to appropriate distinction, that is, to gain status through signalling the high exchange value of the purchased consumption goods or services. Lifestyle preferences and tastes are critical for understanding whether a product can be classified to the special group of commodities that reflect status. In modern times, the formation of lifestyle preferences is determined to a great extent by behavioural forces through the market for culture, especially popular culture. This market includes books, magazines, movies, concerts, sporting events and television programmes. The value of these media arises from the fact that they help shape lifestyle tastes and determine which items are the status goods. The formation of preferences takes place through an individual internalization process, which involves the validation of needs such as self-perception and self-worth. Other psychological forces that are associated with economic activity such as the motive to protect one's own territory are also responsible for the contemporary intensification of the struggle to 'keep up with the Joneses', the phenomenon of relative social competition.

There are evidently behavioural forces, which are inconsistent with rational choice and influence activities that take place in status or positional markets. Those markets are heavily shaped by the activities of an elite group of people. This elite group may include superstars, who are famous and are often viewed as role models, command high fees for their services and offer high-quality services in their profession, and celebrities, who are visible people in the media. The term of superstar markets will be used interchangeably with positional or status markets to emphasize the impact of media visibility attributed to superstars in their occupations and to celebrities, who are famous individuals but are not necessarily successful. Status markets are facilitated by a portion of superstar markets and interface with them, resulting in augmented conspicuous consumption, wrong occupational choices and career inertia.

The trends established by superstars are emulated usually by top-tier consumers, that is, rich consumers. This creates status benchmarks for 
the following tiers of consumers including the lower middle class. Thus status markets exhibit a meaning, which is much broader than the one associated with the purchase of status goods and services alone. This expansion happens because they fully incorporate the impact of behavioural forces and media visibility across superstars, top-tier consumers and the lower social strata in the society. The enhancement provides a social dimension to the analysis of status markets.

For this reason also, the analysis is extended beyond the impact of immediate social comparison at work or in the neighbourhood. Although real-world proximity is an important consideration (that is, to neighbours, co-workers, past classmates and so on), the variability of social identity across individuals is so broad that positional concerns are often expressed in diverse and creative ways that contradict narrow ranking calculations. Superstar markets are generated in segments of consumption and labour markets, in which individual behaviour is influenced endogenously not only by the mere behaviour of other members of the social group in which they belong, such as neighbours and colleagues at work, but also by the strategic processes of identification with the most prominent agents across different occupations, the superstars. These processes are strategic because individuals choose from a large number of superstars to identify with in order to develop a particular sense of social identity. These processes have an impact on individual consumption and occupational choices since the goods or the services associated with the superstars exhibit the highest status or positionality. Thus superstar markets emerge not only because people respond to objective economic motives, but also because they simply hold inflated expectations due to the impact of behavioural processes. The individual propensity to develop an exaggerated social identity beyond one's own resources relates to the utilization as a strategic benchmark of the lifestyles of the most visible and prominent agents, the superstars. Thus the superstars constitute a strategic dominant group in social networks that conveys top status so that positional decision-making of the vast majority of consumers is socially influenced by their signals. This refines the theory of positional markets from a theory of relative concerns to a broader theory of social distinction and discrimination.

Even before capitalism existed, human history was full of economic and social events that arose by the desire to validate an advantage in relative social competition. Today, in remote agricultural villages some form of relative social competition exists by means of material possessions. But what constitutes a remarkable difference from the past is the almost epic advent of the lifestyles of superstars in our mundane everyday life with the aid of new media technologies and the sensational 
experiences that the latter produce not only for the top-tier but also for the bottom-tier consumers. The analysis of these markets not in narrow economic terms but more broadly in psychological, anthropological or even philosophical terms illustrates that the strongest motive to participate in these markets is not merely relative comparison but the possibility to touch the sunshine or to want the moon as Keynes once claimed observing the individual expectations of financial investors. ${ }^{5}$ By analogy to Greek mythology, whereas by becoming heroes people tried to reach the status of gods, the strategic contemporary individual psychological propensity in superstar markets is to emulate some of the status qualities of superstars. Thus the human environment is dominated by new technology and the media visibility that it offers to the most successful professionals, the superstars. The individual internalization of this phenomenon produces the strongest psychological incentive to those willing to participate in markets characterized by tournament forces and relative comparisons. People compare themselves with the 'Joneses' today more than in the past because they are more exposed to what constitutes the ultimate benchmark of relative social competition, the lifestyles and the privileges of the superstars, the virtual Joneses. From a social economy perspective, a valuable area of study is how members of the top class (in terms of income) become first comers in adopting trends from superstars and celebrities. The presence of this top-tier group of consumers of positional goods and services explains the social link between superstars and next-comers in the queue, the Joneses. In such a framework, it is possible to discuss status markets in terms of social groups.

Without a thorough understanding of this mechanism the successful assessment of this phenomenon and the design of appropriate policies can eventually prove ineffective. This phenomenon has become pervasive not only because people seek to match their positional standings to relatives, colleagues, neighbours or friends. Superstars and celebrities are in many ways more useful objects in processes of social competition than people such as neighbours or friends. Since the superstars and celebrities are very well-known and information about them is easier to find and be shared, superstars are like neighbours. ${ }^{6}$ Thus people have developed high expectations of not wanting to be left behind or deprived by what constitutes the ultimate standards as set by superstars' performances and attitudes.

To sum up, in essence the phenomenon of status and superstar markets is expressed through conspicuous consumption, relative social competition and participation in highly rewarding labour markets characterized by risky tournament processes. On the demand side, the relative social competition is associated with the consumption by households of 
distinctive goods and services. On the supply side, these markets are associated with the willingness of households to compete in occupations, which exhibit tournament processes and produce highly visible top earners. Thus visibility is a common denominator in the operation of these markets and relative social competition.

The impact of positional activities is damaging not only because it reduces welfare but also because it produces inequality and relative deprivation. There is in fact a greater burden for lower middle-class individuals and families. When they participate in positional activities the less financially comfortable end up in a worse position. For example, they face greater income losses relative to the privileged, higher levels of financial obligations relative to their income, poorer access to information relative to the contented and take greater risks when it comes to important occupational and investment decisions.

\section{ALTERNATIVE POLICIES AND STATUS MARKETS}

These effects constitute ultimately a high social cost, which can be mitigated through the development of specific policies. In connection to policy formulation, Frank proposes a form of a progressive consumption tax that can potentially support the finance of several horizontal social programmes. These include, for example, better quality standards, better pay for teachers and community workers, and better maintenance of infrastructure. However, the issue of distribution of welfare benefits across different income groups is not addressed in this approach. Thus a substantive area for policy intervention remains open especially if one considers that the distribution impact from government spending has been effective.

The analysis that supports the proposal of the progressive consumption tax stands in between traditional economic analysis, which emphasizes the effectiveness of free markets and alternative progressive approaches, which support state intervention. The first traditional strand includes advocates of orthodox economic theory while the progressive group consists of Keynesians, who support the European social model and post-Keynesians, institutionalists in Veblen's and Galbraith's tradition, Marxists and other radical thinkers. Frank's framework is based on Rosen's seminal work on micro-foundations such as his tournament theory. ${ }^{7}$ Therefore, it stands on the margin of neoclassical equilibrium analysis and non-neoclassical approaches and their presumptions. For example, according to the Austrian school agents, entrepreneurs do have indefinite preferences while in the post-Keynesian approach portfolio 
investors face unexpected opportunities. ${ }^{8}$ Still, those non-neoclassical approaches provide certain interesting insights. For example, in postKeynesian economics, theorists have sought an alternative to neoclassical choice theory by turning to Maslow's hierarchy of needs. ${ }^{9}$ Furthermore, the social theory of Bourdieu has been proposed as an alternative to Maslow's approach, providing the basis for a social critique of consumerism and an alternative evolutionary theory of consumption. ${ }^{10}$ This is essentially a class-based approach in which particular importance is attributed to the role of cultural capital. For those at the bottom of the social hierarchy, culture has a powerful influence over individual expenditure patterns. However, those with higher cultural capital temper their consumption of luxury goods in pursuit of greater status. Thus lifestyles and motives can be better identified across the social hierarchy through instrumental concepts such as, for example, Bourdieu's habitus and through the separation between the cultural and economic capital held by individuals. ${ }^{11}$

\section{SOCIO-ECONOMICS AND THE POLITICAL ECONOMY OF CULTURE CHANGE}

The interest in conspicuous consumption and status markets is not confined only to alternative approaches within the field of pure economics. There is also a large and mainly sociological literature in culture studies that spans from American pragmatism to approaches of French radical sociologists such as Baudrillard, Lyotard and Bourdieu. In the USA, one of the most representative radical sociologists on this issue is Jameson. These thinkers approach the phenomenon of excess consumption and status markets on the basis of the notion of post-modernism. According to this approach, the post-modern era is characterized by an expansion of culture throughout the social domain, to the point at which everything becomes cultural. Those accounts are predominantly of a Marxist orientation and exhibit the same tendency towards emphasizing the inflation of culture. However, they provide a useful link, ignored largely in economic analysis, between culture, media, and the symbols embedded in positional goods of technology and media that provide an 'ecstasy of communication'. This causes the phenomenon of hyperreality where it is no longer possible to distinguish the imaginary from the real. The everyday experience is full of signs, distinctive poses and symbolic meaning. The culture of symbols is expressed by lifestyle preferences and consumption choices that show our own discriminatory judgements of taste to others. In this respect, the symbolism is present not only in the 
design of the production and marketing processes but also in the demand for goods and services. According to this type of analysis, the symbolic associations of goods can be utilized to emphasize differences in lifestyle, which demarcate social as well as class relationships. Thus the phenomenon of superstar markets does not entail solely economic forces such as the impact of earnings growth and technology but also behavioural considerations including the impact of endogenous preferences or meta-preferences in today's virtual world. The analysis that focuses on sociological patterns and philosophical principles makes, as we will see in the following chapters, a convincing case for the role of social discrimination and conflict in status markets, a factor that is overlooked in the economics of 'winner-take-all' society. However, the analysis of European sociological tradition on post-modernism lacks the wealth of economic and psychological empirical evidence associated with the analysis of status markets from an economic viewpoint. As a consequence, it has not yet produced a framework for the formation of concrete policy measures beyond concerns of solidarity and partisanship. The purpose of the present volume therefore is to develop a comprehensive political economy of status markets, in which superstars act as powerful facilitators and to relate it to policies of culture change, which integrates the conclusions from the sociological examination of postmodernism regarding the cultural aspects of social discrimination and conflict with the economic evidence on positional activities.

The method that is followed here is socio-economic in character. ${ }^{12}$ Socio-economics is a method that was supported more notably by worldly philosophers such as Weber, Schumpeter and Lowe in the past. ${ }^{13}$ Since the 1960s, this approach was endorsed by thinkers such as Etzioni, Sen, Simon, Heilbroner and Kahneman. Socio-economics involves the fulfilment of certain conditions such as the pluralism in approaching economic problems and the open interface between economics and other social sciences. ${ }^{14}$ There is an emphasis also on dealing with substantive issues associated with the importance of culture and the complexity of human behaviour, drawing similarities to behavioural economics. Although the term socio-economics in its revival is a relatively new term, there is a rapidly growing number of scholars especially in the USA, who consider themselves socio-economists and who contribute to a growing literature in new journals and books that challenge traditional economic thought.

If it was only a matter of pure economics, superstar markets could be explained by factors such as the impact of new technologies that make possible massive economies of scale and the forces of supply and 
demand. Actually, most economic explanations of the superstar hypothesis, including those of Rosen, Adler and Pesendorfer, focus on the effects of supply-side forces. In this book, the emphasis is on research evidence, which restores the balance because it analyses demand-side effects. Behavioural analysis is especially valuable in this connection because it explains demand-side processes.

The extension of pure economic notions into the realm of society or culture such as the idea of cultural capital and the impact of behavioural forces, allows the consideration of rich evidence from social sciences for the study of superstar markets that is broader than what is defined by traditional economic boundaries. For example, psychological analysis explains meta-preferences while sociological inquiry highlights the role of relative deprivation across different groups of people. Through anthropology, lifestyles and poses of distinction are comprehended as part of individual cultural capital. Political analysis explains effectively the relation between signalling, power and distribution. Philosophical discourse is essential for understanding better the individual need for distinction across different classes. To sum up, the rich evidence from social sciences enriches the economic analysis of positional concerns at a microeconomic level.

\section{THE DESIGN OF NEW POLICIES AND CULTURE CHANGE IN A POLITICAL ECONOMY FRAMEWORK}

The integration of diverse social disciplines leads to insights, conclusions and policy measures that differ from those proposed within the boundaries of standard economics. For example, one important conclusion of the present study is that policy measures should not be confined to the support of social programmes through horizontal measures but should deliver value to those who are at greater disadvantage because of the impact of positional concerns. Therefore, the approach followed here is a cultural political economy framework, which proposes a correction in the form of a redistribution policy. This form of intervention aims at the reduction of economic and social imbalances, which are caused by status markets.

For example, policies can have alternative forms and objectives. They can be designed to support individual motivation, culture change, regulation, monetary rewards and so on. These alternative forms of policies are supported by different analytical concerns. Policies which focus on individual motivation do exhibit a psychological dimension. Monetary and fiscal policies are economic in nature, regulation policies are 
influenced heavily by political factors and culture change policies relate mostly to sociological, anthropological and philosophical considerations. Thus the design of suitable policies mirrors the socio-economic nature of the analysis.

Moreover, as it will be shown in the last chapter of the book, quite often there is interdependence between different categories of economic policies such as taxation, redistribution, regulation and culture change policy. For example, cultural intervention in the form of cultural capital development influences individual behaviour through public programmes that emphasize creativity, productivity and real-life focus at the expense of positional activities and can be financed by the proceedings obtained by the imposition of a progressive consumption tax. Furthermore, culture change policies rely on the political commitment to relate positional waste with redistributive policies, moral leadership and the acknowledgement that culture change and institutional measures can indeed improve social welfare.

\section{CULTURE CHANGE AND CULTURAL POLITICAL ECONOMY}

The political economy of status, superstars and culture change is situated within a broader culture economy, or cultural political economy framework. These accounts provide an interdisciplinary area, which focuses on interactive themes of conventional disciplines and combines approaches to produce enhanced accounts to aid the better understanding of the complexities of the real world. As a result, it helps overcome the constraints imposed by the methods utilized in separate disciplines as is the case, for example, with rational models in economics, in which the application of the principle of complete information is pervasive. In contrast, the framework of culture economy or cultural political economy is pluralist because it is open to all disciplines. More precisely, with regard to the study of status and superstars, I develop an extensive analysis utilizing the rich evidence produced by eclectic economic and mainly behavioural analysis and compelling insights from other disciplines such as psychology, sociology and anthropology to produce open, innovative and pragmatic accounts on this issue. A key feature of this socio-economic expansion is that it highlights the political economy dimensions of positional activities and the role of distribution among different social groups, which belong in different social classes.

There is a divergence of opinions about the precise identity of culture economy, or cultural political economy. The political economy of status 
relates to a broader literature, which includes several alternative attempts to bring forth the importance of culture in economic analysis. These alternative approaches investigate substantive areas that include, nonexhaustively, cultural dimensions of economy, cultural production, cultural anthropology aspects of economy, political economy of culture, culturalization of the economy, cultural aspects of everyday life, cultural theory and policy, cultural norms, economics of habits and conventions, and mainly Marxist accounts of cultural political economy. ${ }^{15}$ There are also evidently other research projects, which highlight the relation between economics and culture.

As I mentioned above, the distributive shares and the underlying conflicts of social groups play an important role and, therefore, the analysis in the present book uses a political economy methodology. However, this account differs from cultural political economy approaches, which adopt Marxism as offering a totalizing perspective on social relations, although it is pluralist and draws important insights from several sources of Marxist origin. More specifically, I envisage cultural political economy in a broader sense to include not only class or social conflict but also other types of conflict of cultural origin such as those embedded in economic, social, cultural and religious systems and their underlying social norms. Thus, the political economy approach followed here is situated within a broader spectrum of conflict theories because it implicitly acknowledges that market economies and liberal or social democracies have succeeded relative to Marxist-related planned modes of social systems and the Soviet experience with regard to wealth creation, improved economic and social conditions, liberal institutions and freedom of expression.

\section{CONCLUDING REMARKS}

Overall, the book develops a political economy theory of status, superstars and culture change. Through its political economy approach, the book enhances in a contemporary context the institutional tradition of Galbraith and Veblen by analysing new evidence from socio-economic (interdisciplinary) research. This approach introduces a new term, status and superstar markets, which refers to segments of consumption and labour markets. In these segments, individual behaviour is influenced endogenously through the media by relative comparisons, strategic considerations and processes of identification with the most prominent and visible agents in positional markets. Visibility and media play an important role because they provide their own context, which feeds behavioural 
(as opposed to rational) aspirations. Technologies extend beyond immediate comparisons such as catching-up with the Joneses. The methodology is based on evidence from behavioural economics, which uses psychological insights rather than rational choice. Behavioural analysis describes specific psychological processes, which show how expectations and aspirations are determined endogenously (short termism, anchoring, cognitive biases, affective and automatic identification, behavioural polarization, deprivation processes, envy and so on) so that rational choice is severely bounded. Psychological analysis explains complex strategic dynamics of emulation in terms of predominantly top-down emulation. Top-tier and bottom-tier consumers in status and superstar markets are associated with social classes bringing to the surface the dynamics of polarization in positional markets and relating it to social inequality and to political economy. The middle class experiences relative deprivation both financially and psychologically in reference to the top social groups when it participates in positional markets. I conclude with effective social policy measures and institutional interventions, situated within a culture change policy, which alleviates social inequalities. While the analysis favours Frank's progressive consumption tax, it develops a cultural capital specificity approach which combines culture change, regulation and taxation.

In the last chapter of the book, the present analysis concludes with social policies for policy-makers that extend beyond the analysis of traditional monetary rewards and costs. Specific policies are identified which correspond to factor-specific cultural capital profiles. Unlike approaches that focus on horizontal programmes, I propose a redistributive culture change policy for different specificities such as the urban community, the youth, the family, the workplace and so on.

To sum up, this book explains how behind the growth of media lies the spread of status and superstar markets, a conceptual framework in which status signals of superstars amplify positional concerns for all, distort the aspirations of the middle class and cause relative deprivation. Building on themes first identified in the institutional tradition by Veblen and Galbraith and supported by modern-day institutionalists, post-Keynesians and political economists, I analyse extensively evidence from behavioural economics and essential modern interdisciplinary research, which contributes constructively to a new genre of economic analysis. The political economy of status and the proposals for culture change compel us to consider seriously effective redistributive public policy proposals targeted to assist the underprivileged and to review the cultural rules for our society. 